\title{
A kinetic study of gamma-glutamyltransferase (GGT)-mediated $S$-nitrosoglutathione catabolism
}

\author{
Valeria Angeli ${ }^{a}$, Alessia Tacito ${ }^{\mathrm{b}}$, Aldo Paolicchi ${ }^{\mathrm{c}}$, Renata Barsacchi ${ }^{\mathrm{b}}$, Maria Franzini ${ }^{\mathrm{d}}$, Riccardo Baldassini ${ }^{\mathrm{c}}$, \\ Cecilia Vecoli ${ }^{\mathrm{d}}$, Alfonso Pompella ${ }^{\mathrm{c}, *}$, Emilia Bramanti $^{\mathrm{a}}$ \\ ${ }^{a}$ National Research Council-CNR, Inst. for Chemico-Physical Processes, Laboratory of Instrumental Analytical Chemistry, Via G. Moruzzi 1-56124 Pisa, Italy \\ ${ }^{\mathrm{b}}$ Department of Biology, Unit of Biochemistry, University of Pisa, Via S. Zeno 51-56127 Pisa, Italy \\ ${ }^{\mathrm{c}}$ Department of Experimental Pathology and BMIE/Sez. Patologia Generale and Clinica, University of Pisa Medical School, Via Roma 55-56126 Pisa, Italy \\ ${ }^{\mathrm{d}}$ Scuola Superiore Sant'Anna, Piazza Martiri della Libertà 33-56127 Pisa, Italy
}

\section{A R T I C L E I N F O}

\section{Article history:}

Received 8 September 2008

and in revised form 15 October 2008

Available online 29 October 2008

\section{Keywords:}

S-Nitrosoglutathione

GSNO

$\gamma$-Glutamyltransferase

GGT

Glutathione

\begin{abstract}
A B S T R A C T
S-Nitrosoglutathione (GSNO) is a nitric oxide (NO) donor compound which has been postulated to be involved in transport of NO in vivo. It is known that $\gamma$-glutamyl transpeptidase (GGT) is one of the enzymes involved in the enzyme-mediated decomposition of GSNO, but no kinetics studies of the reaction GSNO-GGT are reported in literature.

In this study we directly investigated the kinetics of GGT with respect to GSNO as a substrate and glycyl-glycine (GG) as acceptor co-substrate by spectrophotometry at $334 \mathrm{~nm}$. GGT hydrolyses the $\gamma$-glutamyl moiety of GSNO to give $S$-nitroso-cysteinylglycine (CGNO) and $\gamma$-glutamyl-GG. However, as both the substrate GSNO and the first product CGNO absorb at $334 \mathrm{~nm}$, we optimized an ancillary reaction coupled to the enzymatic reaction, based on the copper-mediated decomposition of CGNO yielding oxidized cysteinyl-glycine and NO. The ancillary reaction allowed us to study directly the GSNO/GGT kinetics by following the decrease of the characteristic absorbance of nitrosothiols at $334 \mathrm{~nm}$. A $K_{\mathrm{m}}$ of GGT for GSNO of $0.398 \pm 31 \mathrm{mM}$ was thus found, comparable with $K_{\mathrm{m}}$ values reported for other $\gamma$-glutamyl substrates of GGT.
\end{abstract}

(c) 2008 Elsevier Inc. All rights reserved.

\section{Introduction}

Gamma-glutamyl transpeptidase (GGT; E.C. 2.3.2.2) ${ }^{1}$ is a wellcharacterized type II heterodimeric glycoprotein anchored to the outside surface of the plasma membrane of both plant and animal cells. GGT catalyses the transfer of a $\gamma$-glutamyl moiety from the in vivo donor substrate, glutathione (GSH), to an active site nucleophile to form an acyl-enzyme intermediate during the acylation step of its catalytic cycle. This intermediate can then react, during the deacylation step, with an acceptor substrate containing a free amino group (normally an alpha amino acid) to form a new $\gamma$-glutamyl isopeptide bond and regenerate the free enzyme. In the absence of a primary amine acceptor substrate, the acyl-enzyme reacts slowly with water, giving a ping-pong catalytic cycle, modified to include hydrolytic deacylation [1].

\footnotetext{
* Corresponding author. Fax: +390502218557.

E-mail address: apompella@biomed.unipi.it (A. Pompella).

1 Abbreviations used: GGT, $\gamma$-glutamyltransferase; GSNO, S-nitrosoglutathione; NO, nitric oxide; GG, glycyl-glycine; CGNO, S-nitroso-cysteinylglycine; NEM, N-ethylmaleimide; DTPA, diethylentriamine-pentaacetic acid pentasodium salt; PBS, phosphate buffer solution.
}

GGT is mainly known as a central enzyme for the metabolism of GSH [2,3], although studies from the latest decade have highlighted its wider influence on cellular and extracellular redox equilibria [4].

S-Nitrosoglutathione (GSNO) results from nitrosation of GSH, and several reports have proposed its involvement in storage and transport of NO [5,6], as well as a mediator of its endocrine effects of NO $[7,8]$. Several authors have hypothesized that GGT is involved in in vivo GSNO decomposition $[9,10]$. However, the kinetic parameters $\left(K_{\mathrm{m}}^{\mathrm{GSNO}}, V_{\mathrm{max}}, K_{\text {cat }}\right)$ of this reaction have not yet been reliably assessed.

In this study the kinetics of the reaction GSNO/GGT was investigated by a new spectrophotometric method, based on the coupling of two reactions: (i) the enzymatic cleavage of GSNO to CGNO, and (ii) the release of NO from CGNO mediated by copper ions. As both substrate GSNO and product GCNO actually present with the same characteristic absorption at $334 \mathrm{~nm}$, previous studies have employed chromatographic separation of the reaction mixture prior to analysis and quantification [9]. Our method in fact avoids this need, insofar as the $\mathrm{Cu}(\mathrm{II})$-mediated decomposition of CGNO allows to follow GGT enzyme activity by UV/visible spectrophotometry, directly as a decrease of absorbance at $334 \mathrm{~nm}$. 


\section{Materials and methods}

\section{Chemicals}

Analytical reagent-grade chemicals were used without further purification. GGT (G-8040, Type I crude from bovine kidney), glycyl-glycine (GG, G-1002) and glutamic acid 5-(3-carboxy-4-nitroanilide) ammonium salt (Glu-cp-NA, BioChemika 49525), a synthetic substrate for GGT, were purchased from Sigma-Aldrich (Sigma, Chemical Co., Milan, Italy). Copper sulfate, anhydrous (2791) was purchased from Merck (Laborchimica, Firenze, Italy). $N$-Ethylmaleimide (NEM, 04259 BioChemika Ultra, $\geqslant 99.0 \%$ ) and diethylentriamine-pentaacetic acid pentasodium salt (DTPA, 17969) were purchased from Fluka (Fluka GmbH, Buchs, Switzerland).

$\mathrm{CuSO}_{4}$ and NEM stock solutions were prepared in MilliQ water. NEM solution was prepared daily.

Phosphate buffer solution (PBS) was prepared from monobasic monohydrate sodium phosphate and dibasic anhydrous potassium phosphate (BDH Laboratory Supplies, Poole, England). GGT stock solutions were prepared in $0.1 \mathrm{M}$ PBS pH 8.0. GG stock solution was prepared in $1 \mathrm{M}$ PBS $\mathrm{pH}$ 8.0.

Stock solution of GSNO (N4148, CAS No. 57564-91-7, Sigma) was prepared in $0.1 \mathrm{M}$ PBS $\mathrm{pH}$ 8.0. In these experimental conditions GSNO standard solution was stable during the working day ( $9 \mathrm{~h}$ time, tested at room temperature) and for 4 weeks if stored at $-80^{\circ} \mathrm{C}$.

GSNO and CGNO were prepared by reacting $1 \mathrm{M} \mathrm{NaNO}_{2}$ in $\mathrm{H}_{2} \mathrm{O}$ with $1.1 \mathrm{M}$ thiols in $0.5 \mathrm{M} \mathrm{HCl}, 0.5 \mathrm{mM}$ EDTA at $0{ }^{\circ} \mathrm{C}$ for $40 \mathrm{~min}$ [11], and used after measuring their concentration from the absorbance measured at $334 \mathrm{~nm}$, using the extinction coefficient $977 \mathrm{M}^{-1} \mathrm{~cm}^{-1}$ [12]. RSNOs were diluted in $0.1 \mathrm{M}$ PBS $\mathrm{pH}$ 8.0, $0.5 \mathrm{mM}$ DTPA and their stability tested before any other use.

Methanol for liquid chromatographic analysis was purchased from Carlo Erba (Rodano, MI, Italy). Water deionized with a MilliQ system (Millipore, Bedford, MA, USA) was used throughout.

\section{Measurements of GGT activity}

GGT activity was determined by following the hydrolysis of Glu-cp-NA as previously described [2]. Briefly, purified enzyme was incubated with Glu-cp-NA (1 mM) and GG $(20 \mathrm{mM})$ in PBS $(0.1 \mathrm{M}, \mathrm{pH} 8.0)$ at $37{ }^{\circ} \mathrm{C}$ and the increase in absorbance at $405 \mathrm{~nm}$ was monitored. Enzyme activity was determined using a molar absorption coefficient of $8800 \mathrm{M}^{-1} \mathrm{~cm}^{-1}$ for formation of $p$ nitroaniline.

\section{Spectrophotometric analysis}

GSNO and CGNO decomposition measurements were made spectrophotometrically in $0.1 \mathrm{M} \mathrm{PBS} \mathrm{pH} 8.0$ at $37 \pm 0.1^{\circ} \mathrm{C}$ by a Beckman DU-600 spectrophotometer, following the decrease of $334 \mathrm{~nm}$ absorbance. Values of rate constants are means of at least three determinations, and the standard error was always better than $\pm 3 \%$. Autozero was performed on solutions before adding GSNO. After absorbance stabilization the enzyme was added.

\section{HPLC analysis}

The reaction of GGT and GSNO was followed also by HPLC, by sampling the reaction solution at various time points and quenching the reaction by the addition of $1 \mathrm{M} \mathrm{HCl}$ followed by centrifugation. The HPLC unit consisted of a pump (P4000, ThermoQuest) equipped with a mechanical degassing system (SC1000, ThermoQuest, Milan, Italy), a Rheodyne 7125 injector (Rheodyne, Cotati,
CA, USA), a $20 \mu \mathrm{L}$ injection loop, a diode array detector equipped with a $5 \mathrm{~cm}$ path length flow cell (DAD, UV6000, ThermoQuest), and a column (Gemini RP $\mathrm{C}_{18} 250 \times 4.6 \mathrm{~mm}$, silica particle size $5 \mu \mathrm{m}$, equipped with a Guard Cartridge KJ0-4282, Phenomenex). The eluent for analysis was 97\% 0.02 M PBS pH 6.0/3\% methanol (97:3 v/v), flowing at $1 \mathrm{~mL} / \mathrm{min}$. Column effluent was monitored by absorbance at $334 \mathrm{~nm}$. GSNO and CGNO were quantified by reference to authentic standards. All the solutions were filtered by $0.45 \mu \mathrm{m}$ cellulose acetate filters (Microcon, Millipore Corporation).

\section{Results and discussion}

\section{Principles of the spectrophotometric method}

In preliminary experiments we observed that GSNO affects the kinetics of the reaction between GGT and $\gamma$-Glu-cp-NA. Spectrophotometric kinetics at $405 \mathrm{~nm}$ performed in 0.1 M PBS pH 8.0, $4.5 \mathrm{mM}$ GG at $37^{\circ} \mathrm{C}$, in the absence and presence of three different concentrations of GSNO, in fact showed that GSNO, being a $\gamma$-Glu donor, behaves like a competitive inhibitor in the $\gamma$-Glu-cp-NA/ GGT reaction. Fig. 1A shows the double reciprocal plots of data corresponding to these experiments. The $K_{\mathrm{I}}$ value for GSNO $(309 \pm 34 \mu \mathrm{M})$ was calculated from the double reciprocal plot by applying the Eq. (1) (Fig. 1B):

$\alpha=1+\frac{[\mathrm{I}]}{K_{\mathrm{I}}}$

where $\alpha$ corresponds to the ratio of the slopes of the uninhibited and inhibited reactions. Thus, we designed a spectrophotometric study for the determination of the kinetics parameters of the reaction.

Hogg et al. demonstrated that GGT stimulated the release of NO from GSNO in the presence of a transition metal (copper being the most effective) [9]. The enzymatic mechanism did not result however in the release of NO if chelating agents (such as DTPA or EDTA) were present in the reaction medium. This result can be explained by the different stability of GSNO as compared to CGNO (the first product of the enzymatic transnitrosation reaction) toward copper ion-catalysed decomposition. The reaction of $\mathrm{Cu}$ (II) with CGNO is very rapid, with half-lives of about $5 \mathrm{~s}$, while reaction of GSNO is 3-4 orders of magnitude slower [13].

On this basis, we optimized suitable operating conditions in order to follow the enzymatic reaction (2) by an ancillary reaction (reaction (3)) based on the copper-catalyzed decomposition of CGNO:

$$
\begin{aligned}
& \mathrm{GSNO}+\mathrm{GG} \stackrel{\mathrm{GGT}}{\longrightarrow} \mathrm{CGNO}+\gamma-\mathrm{GluGG} \\
& \mathrm{CGNO} \stackrel{\mathrm{CuSO}_{4}}{\longrightarrow} \mathrm{NO}+\mathrm{CG}_{\mathrm{ox}}
\end{aligned}
$$

where glycyl-glycine (GG) was chosen as acceptor substrate of GGT. Reaction (3) is fast as compared to reaction (2) [13], thus allowing to follow the enzymatic reaction by the decrease of the absorbance at $334 \mathrm{~nm}$.

Fig. 2 reports UV/visible absorbance spectra of GGT solution and GSNO/GGT/Cu(II) reaction mixture, before and after the addition of transpeptidation acceptor GG. The enzyme is responsible for the absorption band around $280 \mathrm{~nm}$ (spectrum a), GSNO for the band at $334 \mathrm{~nm}$ (spectrum b). As expected, GGT activity decreased the absorption band at $334 \mathrm{~nm}$ (spectrum c, 10 min reaction).

Fig. 3 reports the time-dependent plots of the enzymatic decomposition of GSNO by GGT, in absence or presence of $\mathrm{CuSO}_{4}$ and GGT. In the absence of GGT (Fig. 3, curve a') $\mathrm{Cu}(\mathrm{II})$ itself did not decompose GSNO in the 5 min observation time, in agreement with previous literature data [13]. In the presence of GGT, GSNO was hydrolyzed to CGNO, which decomposed slowly (Fig. 3, curve 

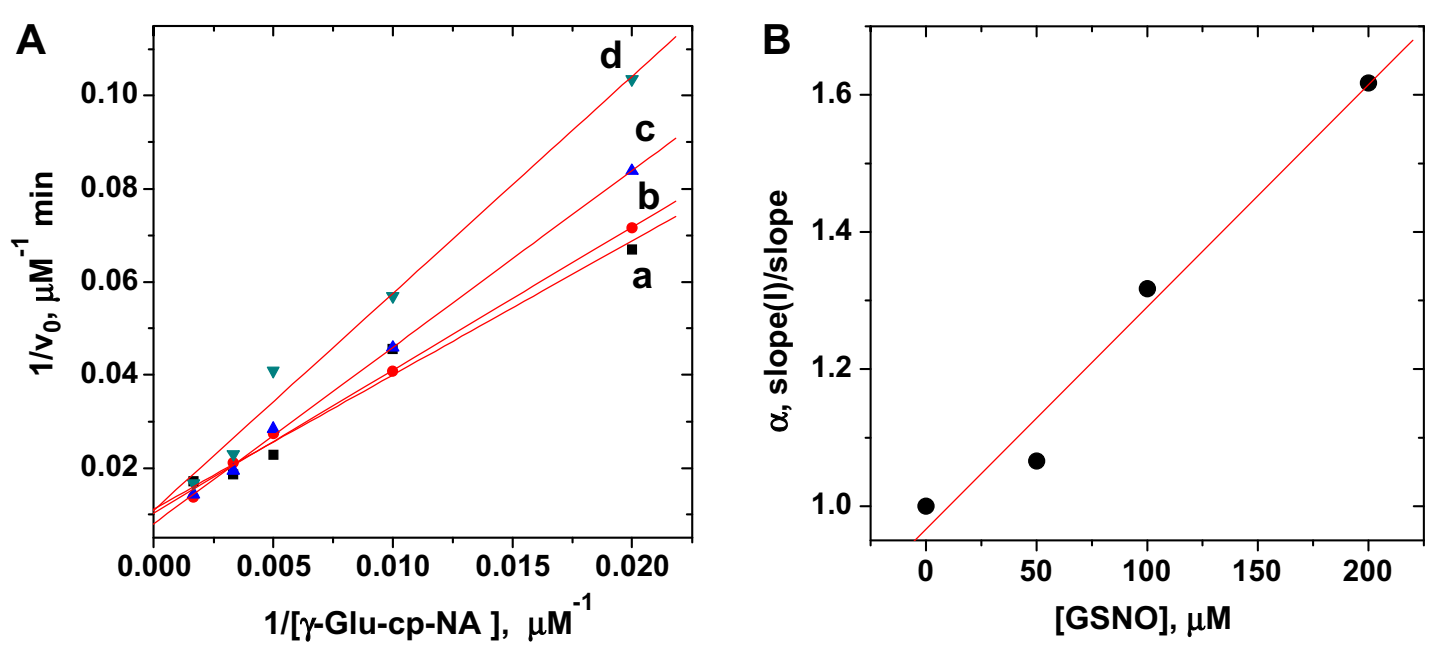

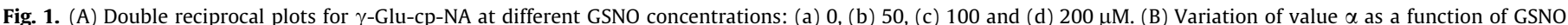
concentration (intercept $=0.966 \pm 0.042$, slope $=0.00324 \pm 0.00036, R=0.9877$ ).

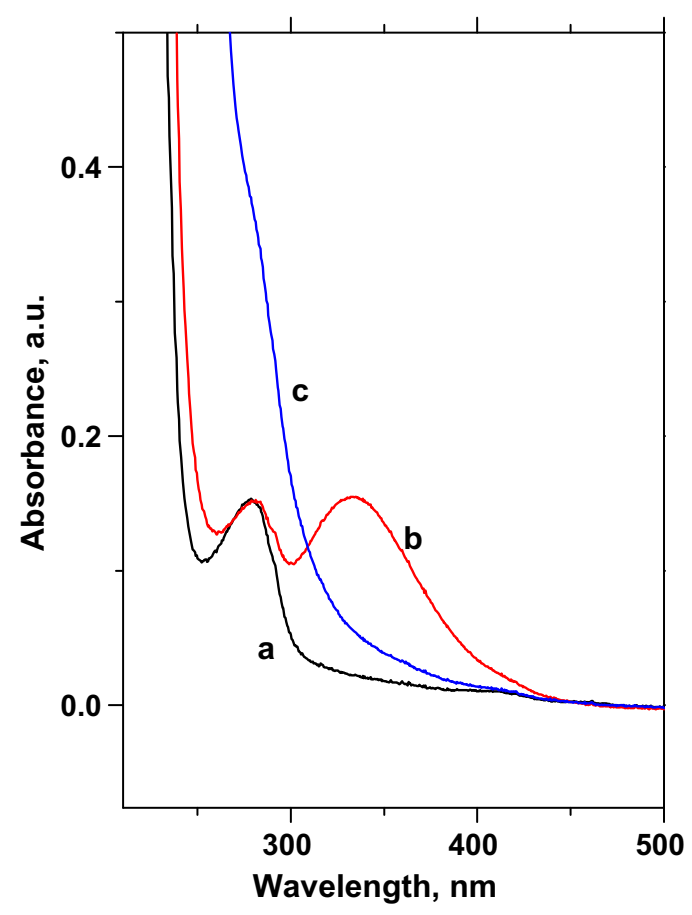

Fig. 2. UV/visible absorbance spectra of $525 \mathrm{mU} \mathrm{mL}^{-1} \mathrm{GGT}$ in $0.1 \mathrm{M} \mathrm{PBS} \mathrm{pH} 8.0$, at $37^{\circ} \mathrm{C}$ (a), $525 \mathrm{mU} \mathrm{mL}^{-1} \mathrm{GGT}, 100 \mu \mathrm{M}$ GSNO, $0.1 \mathrm{mM} \mathrm{Cu(II)}$ reaction mixture before (b) and $10 \mathrm{~min}$ after the addition of $4.5 \mathrm{mM}$ acceptor substrate GG (c).

a). This was likely due to transition metals accidentally present in the reaction medium, as confirmed by the complete inhibition obtained by the addition of EDTA ( $0.5 \mathrm{mM}$, data not shown). On the other hand, in the presence of $\mathrm{Cu}(\mathrm{II}) \mathrm{CGNO}$ was rapidly decomposed (Fig. 3, curve b).

In order to verify if $\mathrm{Cu}(\mathrm{II})$ affects the enzymatic reaction, we (i) studied the kinetics $\gamma$-Glu-cp-NA/GG/GGT in the presence or absence of $\mathrm{Cu}(\mathrm{II})$, and (ii) analyzed the reaction products by HPLC, alternatively in the presence of DTPA or $\mathrm{Cu}(\mathrm{II})$. The presence of $\mathrm{Cu}$ (II) did not significantly affect enzyme activity (Fig. 4). In the HPLC experiments, the enzymatic reaction was stopped at different times by adding $\mathrm{HCl}(0.5 \mathrm{M}$ final concentration) and analysing the reaction mixture after ultrafiltration. Fig. 5 shows the absorbance chromatograms at $334 \mathrm{~nm}$ of the reaction products after $0.5,1$

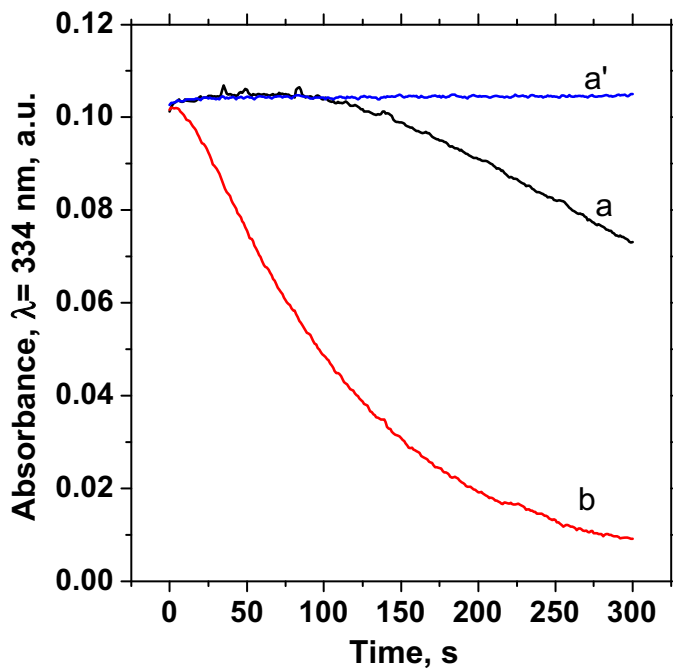

Fig. 3. Time-dependent plots of enzymatic decomposition of $100 \mu \mathrm{mol} \mathrm{L}^{-1}$ GSNO in $0.1 \mathrm{~mol} \mathrm{~L}^{-1} \mathrm{PBS} \mathrm{pH} 8.0$, at $37^{\circ} \mathrm{C}$, by $525 \mathrm{mU} \mathrm{mL}^{-1} \mathrm{GGT}, 4.5 \mathrm{mM}$ GG, with and without $\mathrm{CuSO}_{4}$ : (a) $0 \mu \mathrm{M}$, (b) $100 \mu \mathrm{M}$. In a' the buffer contained $\mathrm{CuSO}_{4} 100 \mu \mathrm{M}$, but GGT was omitted.

and 5 min after addition of the enzyme (panel A), and the time-dependent plots obtained by plotting areas of CGNO and GSNO peaks (at $6.69 \pm 0.01$ and $7.21 \pm 0.01$ min, respectively; panel B). The assignment of chromatographic peaks to CGNO and GSNO was based on the injection of standard solutions of pure compounds of known concentration measured by UV $\left(\varepsilon_{334}=\right.$ $977 \mathrm{M}^{-1} \mathrm{~cm}^{-1}$ ) [12], and quantitation was based on calibration curves. As can be seen in Fig. 5A (in the presence of DTPA), both CGNO and GSNO peaks can be observed, the first increasing, the latter decreasing as the reaction proceeds. In the presence of $0.1 \mathrm{mM} \mathrm{Cu}(\mathrm{II})$ only the GSNO peaks were observed, because of the rapid decomposition of CGNO. The rate of GGT-mediated GSNO metabolism was however not significantly affected (Fig. 5B). Thus, on the basis of these results we can conclude that copper does not interfere with the enzyme kinetics.

\section{Kinetic parameters of GSNO/GGT reaction}

The ancillary reaction (copper-mediated CGNO decomposition) was used to determine spectrophotometrically the kinetics param- 


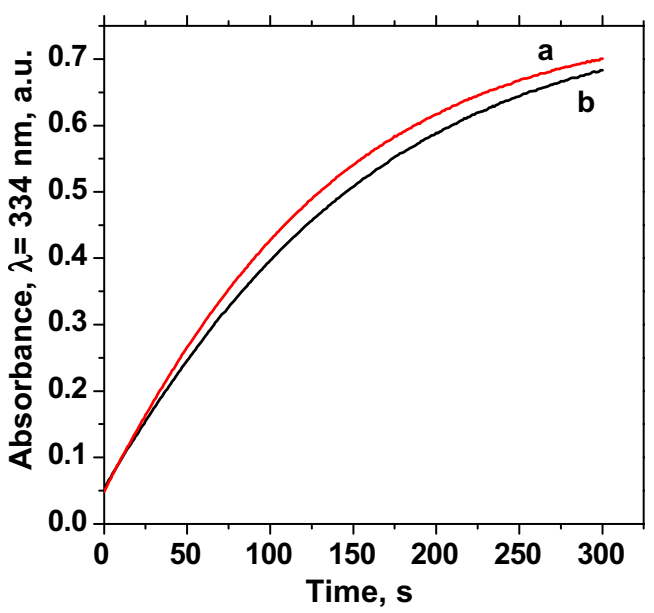

Fig. 4. Time-dependent plots of enzymatic hydrolysis of $100 \mu \mathrm{M} \gamma$-Glu-cp-NA in $0.1 \mathrm{~mol} \mathrm{~L}^{-1} \mathrm{PBS} \mathrm{pH} 8.0$, at $37^{\circ} \mathrm{C}$, by $525 \mathrm{mU} \mathrm{mL}^{-1} \mathrm{GGT}, 4.5 \mathrm{mM} \mathrm{GG}$ without (curve a) and with $100 \mu \mathrm{M} \mathrm{Cu}(\mathrm{II})$.

eters of the GGT/GSNO reaction. $K_{\mathrm{m}}$ was determined at a fixed concentration of the enzyme, by varying the GSNO concentrations between 50 and $300 \mu \mathrm{M} . K_{\mathrm{m}}$ and $V_{\max }$ for GSNO were estimated by linear regression from the double reciprocal plot.

$K_{\mathrm{m}}$ values were derived from kinetics repeated in different operating condition: $\mathrm{Cu}(\mathrm{II})$ concentration varying from 50 to $600 \mu \mathrm{M}$, GG from 4.5 to $20 \mathrm{mM}$, and GGT from 200 to 525 and $1000 \mathrm{mU} /$ $\mathrm{mL}$. Different concentrations of $\mathrm{Cu}(\mathrm{II})$ were used in order to ascertain that the presence of the metal did not affect the enzymatic kinetics, while different concentrations of acceptor substrate were used to verify that glycyl-glycine did not affect $\mathrm{Cu}(\mathrm{II})$-mediated CGNO decomposition. It was thus possible to calculate an average $K_{\mathrm{m}}$ value equal to $390 \pm 30 \mu \mathrm{M}(N=9$ experiments, with $\mathrm{Cu}(\mathrm{II})$ concentrations of $50,100(N=6), 200$ and $600 \mu \mathrm{M})$, and a $V_{\max }$ value equal to $165 \pm 16 \mu \mathrm{M} / \mathrm{min}$ ( $N=6$ experiments with $525 \mathrm{mU} / \mathrm{mL}$ GGT; varying concentrations of $\mathrm{Cu}(\mathrm{II})$ and acceptor did not affect the results).

Being aware of the uncertainty deriving from analysis of kinetic parameters using crude enzyme preparations, we also determined $K_{\mathrm{m}}$ for the synthetic substrate $\gamma$-Glu-cp-NA using the same lot of commercial GGT. A value of $301 \pm 9 \mu \mathrm{M}$ was found, in agreement with values reported in literature for the same substrate ranging between 210 and $650 \mu \mathrm{M}$, depending on GGT source and reaction conditions [14-17].

$K_{\mathrm{m}}$ for GG was also determined, by keeping constant the concentrations of the enzyme $(525 \mathrm{mU} / \mathrm{mL})$ and GSNO $(100 \mu \mathrm{M})$, while varying GG concentrations from 0.5 to $8 \mathrm{mM}$. The fitting of data of the linear part of the double reciprocal plot gave in this case a $K_{\mathrm{m}}$ value of $687 \pm 63 \mu \mathrm{M}$.

\section{Effect of GSNO on $\gamma$-Glu-cp-NA/GGT reaction}

In order to confirm the reliability of the $K_{\mathrm{m}}$ value found for the GSNO/GGT reaction, we studied the kinetics of the reaction $\gamma$-Glucp-NA/GGT in the presence of 0, 50, 100 and $200 \mu \mathrm{M}$ GSNO. $K_{\mathrm{m}}$ was determined at a fixed concentration of the enzyme $(525 \mathrm{mU} / \mathrm{mL})$, by varying the $\gamma$-Glu-cp-NA concentrations between 50 and $600 \mu \mathrm{M}$. $K_{\mathrm{m}}$ and $V_{\max }$ for $\gamma$-Glu-cp-NA were estimated by linear regression from the double reciprocal plot.

The results showed that GSNO acts as a competitive inhibitor of the reaction. From the ratio of the slopes of regression lines from the double reciprocal plot obtained with/without GSNO slope $_{\mathrm{GSNO}} /$ slope $_{0}=\alpha$ ) it is possible to calculate $K_{\mathrm{l}}$, according to the equation:

$\alpha=1+\frac{[\mathrm{I}]}{K_{\mathrm{I}}}$

where $K_{\mathrm{I}}$ is the dissociation constant of the EI complex $\left(K_{\mathrm{I}}=[\mathrm{E}][\mathrm{I}] /\right.$ [EI]).

Fig. 6 is a plot of the ratio $\alpha$ as a function of GSNO concentration. From linear fitting of data, an intercept $=0.966 \pm 0.04$ and a slope $=0.00324 \pm 0.00036(R=0.9877)$ are calculated, corresponding to a $K_{\mathrm{I}}=309 \pm 34 \mu \mathrm{M}$. This value is in good agreement with the $K_{\mathrm{m}}$ value for GSNO reported above. It is in fact accepted that $K_{\mathrm{I}}\left(K_{\mathrm{I}}=k_{-1} / k_{+1}\right)$ by definition is $<K_{\mathrm{m}}$ :

$K_{\mathrm{m}}=\frac{k_{-1}+k_{2}}{k_{1}}$

\section{Determination of $K_{\text {cat }}$ of GGT for GSNO}

A valuable catalytic constant in addition to $K_{\mathrm{m}}$ and $V_{\max }$ is the turnover coefficient $K_{\text {cat }}$, defined as:

$K_{\text {cat }}=V_{\max } /[\mathrm{Et}]$

where [Et] is the total enzyme concentration.

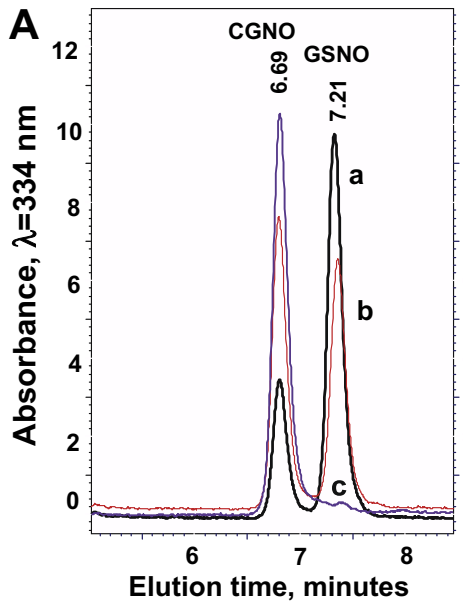

B

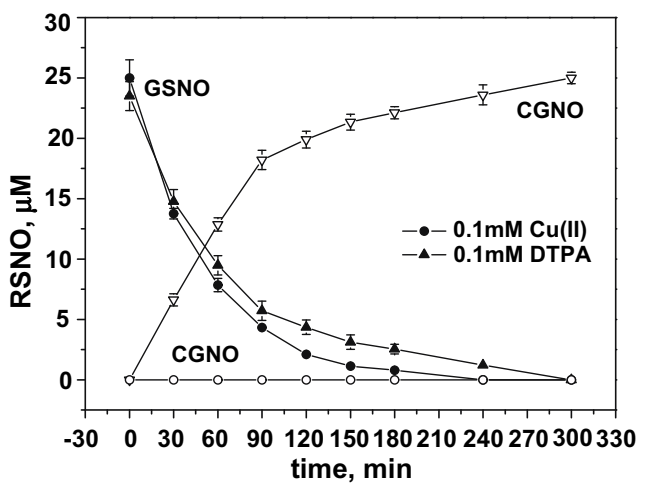

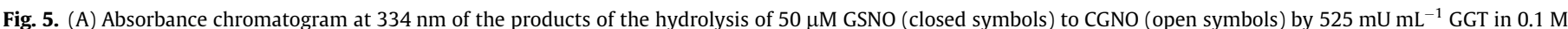

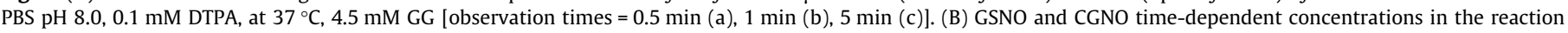
mixture analysed by HPLC in experiments similar to that represented in (A), in the presence of $0.1 \mathrm{mM} \mathrm{CuSO}_{4}$ (circles) and $0.1 \mathrm{mM}$ DTPA (triangles). 


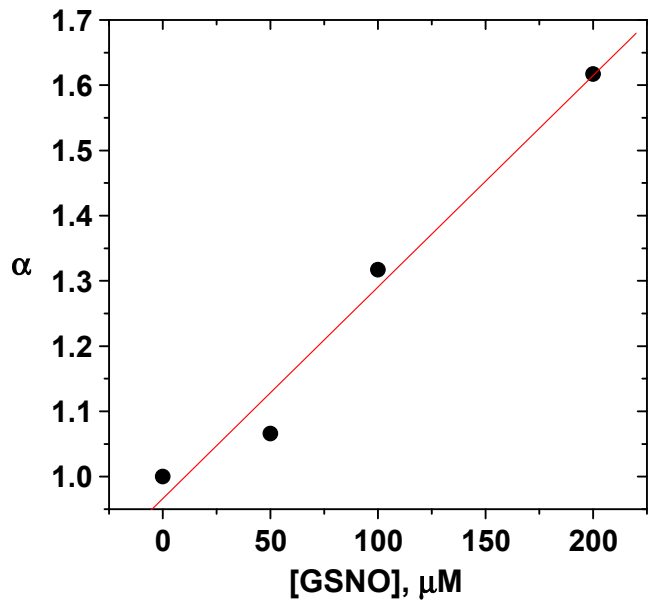

Fig. 6. Inhibitory effect of GSNO on the $\gamma$-Glu-cp-NA/GGT reaction. Plot of $\alpha(=1+$ $\left.[\mathrm{I}] / \mathrm{K}_{\mathrm{I}}\right)$ as a function of GSNO concentration. $R=0.9877$, intercept $=0.9663 \pm 0.042$, slope $=0.00324 \pm 0.00036$.

$K_{\text {cat }}$ was calculated from our data following two different approaches: (i) form the slope of the plot $V_{\max }$ as a function of [Et] (Fig. 7A); (ii) by plotting $V_{0}$ as a function of GGT concentration at fixed, non-saturating concentrations of GSNO (Fig. 7B), by the equation:

$V_{0}=\frac{K_{\mathrm{cat}}[\mathrm{S}]}{K_{\mathrm{m}}}[\mathrm{Et}]$

where we can reasonably assume that $[\mathrm{S}]=\left[\mathrm{S}_{0}\right]$ at $t=0$.

With the procedure (i), a value of $K_{\text {cat }}=(2.88 \pm 0.03)$

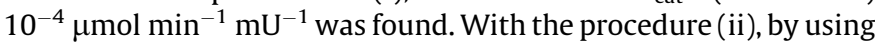
the $K_{\mathrm{m}}$ value calculated above $(386 \pm 30 \mu \mathrm{M})$, a fully comparable va-

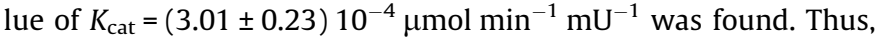
the two procedures employed yielded fully comparable results, which represents an independent confirmation of the validity of the $K_{\mathrm{m}}$ value calculated by the spectrophotometric method described above.
Regulation of GSNO/GGT reaction by transpeptidation acceptor: the ratio GSNO/GG

As concentrations of both $\gamma$-glutamyl donor and acceptor substrates concur in regulation of GGT activity $[14,18]$, we studied the GGT/GSNO reaction by varying the concentrations of donor GSNO, in the presence of different GG/GSNO ratios (Fig. 8).

In the absence of GG (curve a) the reaction proceeded slowly$\gamma$-glutamyl groups being transferred to water acting as acceptor [14,19]-up to GSNO > $175 \mu \mathrm{M}$, when $V_{0}$ was likely inhibited by donor substrate. For $\mathrm{GG} / \mathrm{GSNO}=0.5$ (curve b), GSNO was little decomposed and $V_{0}$ was independent of GSNO concentration; this might be due to enzyme inactivation by $\mathrm{Cu}(\mathrm{II})-\mathrm{GG}$ complexes: GG is in fact known to form complexes with copper [20]. Only for GG/ GSNO ratio $=15$ (curve d) we observed a $K_{\mathrm{m}}=380 \mu \mathrm{M}$ (double reciprocal plot fitting parameters: slope $=3.538 \pm 0.266$, intercept $=0.0093 \pm 0.003, V_{\max }=107 \mu \mathrm{M} / \mathrm{min} ; R=0.9916, N=5$ ), i.e., a value in agreement with data reported above.

\section{Concluding remarks}

Despite the envisaged role of GSNO as the physiological substrate for GGT activity, to date the kinetics of the reaction of GGT with GSNO as substrate had not been investigated in full detail, probably due to the difficulty of detecting the reaction product CGNO. The latter compound in fact presents with the same absorption at $334 \mathrm{~nm}$ as the substrate GSNO itself, which required the introduction of a HPLC separation step in order to perform quantification [9]. On the other hand, the method described in this study overcomes product detection problems and permits straightforward determination of GGT-mediated GSNO metabolism, giving therefore more reliable kinetics parameters for the GSNO/GGT reaction. In our assay conditions an apparent $K_{\mathrm{m}}$ of $386 \pm 30 \mu \mathrm{M}$ was calculated for the GGT/GSNO reaction, using commercial bovine kidney GGT and GG as transpeptidation acceptor. This value is closely comparable with GGT $K_{\mathrm{m}}$ values reported in literature for synthetic substrates such as $\gamma$-glutamyl-p-nitroanilide (610$680 \mu \mathrm{M}, \quad[21]), \quad \gamma$-glutamyl-3-carboxy-4-nitroanilide $\quad(370 \mu \mathrm{M}$ [15]), as well as its physiological substrate GSH (400 $\mu \mathrm{M}$ [22]), thus suggesting that GGT may have a role in GSNO metabolism. A signif-
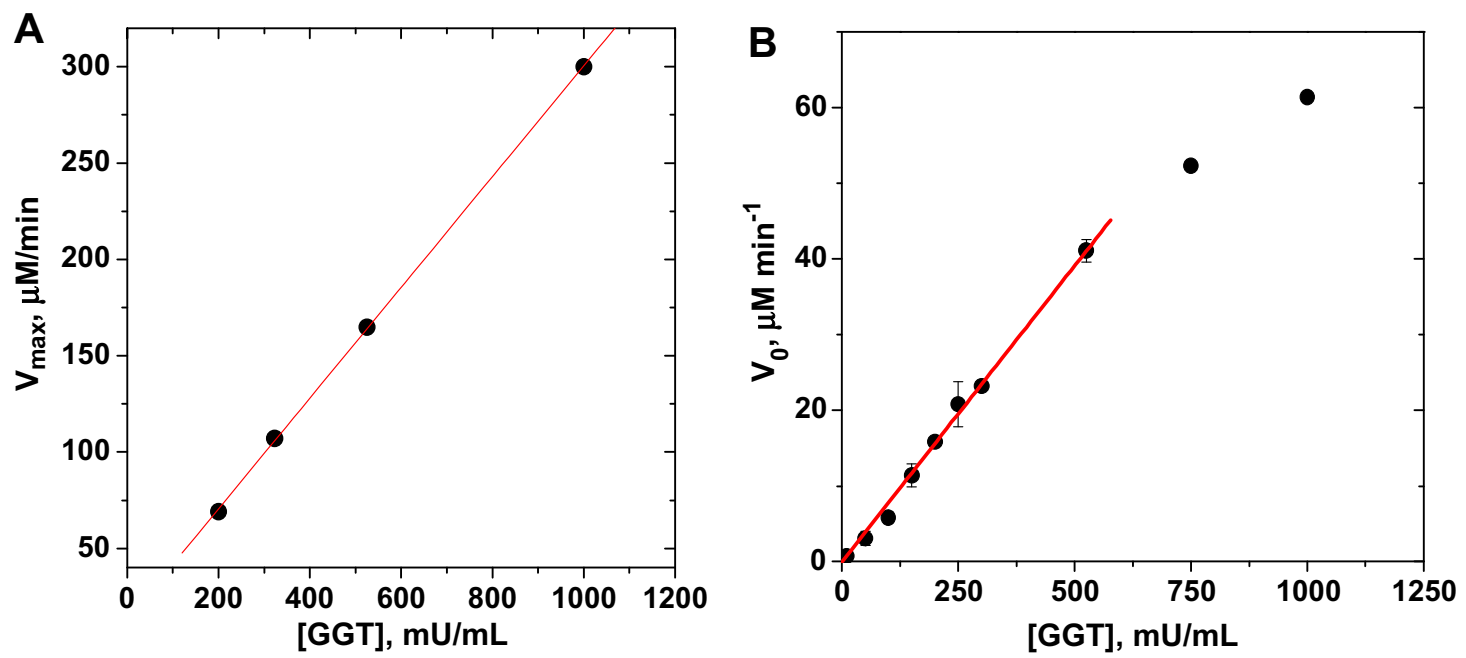

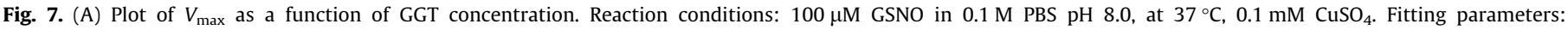

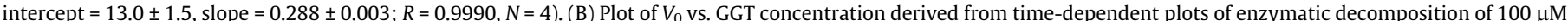

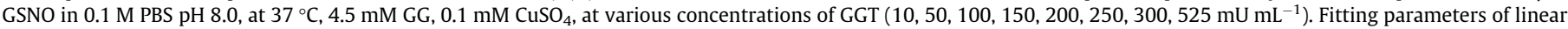
part: slope $=0.078 \pm 0.0014 ; R=0.9979, N=8$ ). 


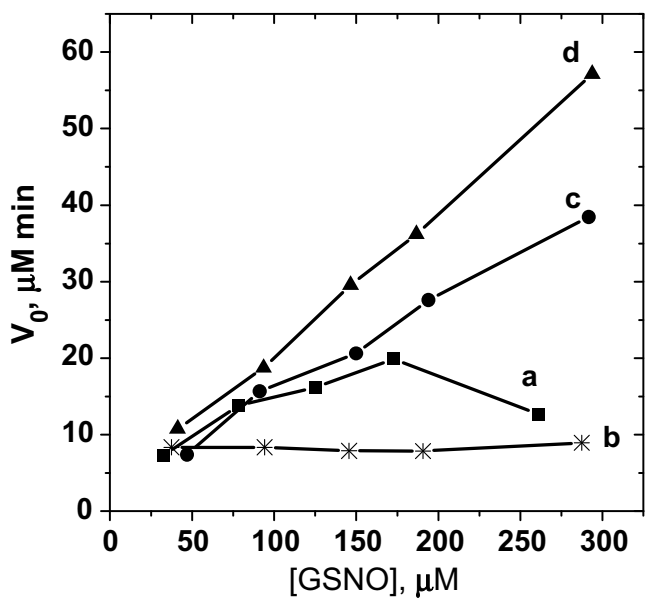

Fig. 8. Plot of $V_{0}$ as a function of GSNO concentration at different constant GG/GSNO ratios: (a) $G G=0$, (b) GG/GSNO $=0.5$, (c) GG $/ G S N O=5$, (d) GG $/ G S N O=15$. Reaction conditions: $323 \mathrm{mU} / \mathrm{mL}$ GGT, $0.1 \mathrm{mM} \mathrm{Cu}(\mathrm{II})$ in $0.1 \mathrm{M}$ PBS $\mathrm{pH} 8.0,37^{\circ} \mathrm{C}$.

icant association of serum GGT values with evolution of cardiovascular diseases has been repeatedly reported [23]. The possibility thus exists that an altered GSNO handling may occur in these patients; further studies are clearly needed to investigate this hypothesis.

\section{References}

[1] J.W. Keillor, R. Castonguay, C. Lherbet, Meth. Enzymol. 401 (2005) 449-467.
[2] A. Meister, S.S. Tate, O.W. Griffith, Meth. Enzymol. 77 (1981) 237-253.

[3] A. Pompella, A. Visvikis, A. Paolicchi, V. De Tata, A.F. Casini, Biochem. Pharmacol. 66 (2003) 1499-1503.

[4] S. Dominici, A. Paolicchi, A. Corti, E. Maellaro, A. Pompella, Meth. Enzymol. 401 (2005) 483-500.

[5] J.S. Stamler, Circ. Res. 94 (2004) 414-417.

[6] A.R. Butler, P. Rhodes, Anal. Biochem. 249 (1997) 1-9.

[7] B. Datta, T. Tufnell-Barrett, R. A Bleasdale, C.J. Jones, I. Beeton, V. Paul, M. Frenneaux, P. James, Circulation 109 (2004) 1339-1342.

[8] J.W. Elrod, J.W. Calvert, S. Gundewar, N.S. Bryan, D.J. Lefer, Proc. Nat. Acad. Sci. USA 105 (2008) 11430-11435.

[9] N. Hogg, R.J. Singh, E. Konorev, J. Joseph, B. Kalyanaraman, Biochem. J. 323 (1997) 477-481.

[10] H. Al-Sa'doni, A. Ferro, Clin. Sci. 98 (2000) 507-520.

[11] A. Doctor, R. Platt, M.L. Sheram, A. Eischeid, T. McMahon, T. Maxey, J. Doherty, M. Axelrod, J. Kline, M. Gurka, A. Gow, B. Gaston, Proc. Natl. Acad. Sci. USA 102 (2005) 5709-5714.

[12] W.R. Mathews, S.W. Kerr, J. Pharmacol. Exp. Toxicol. 267 (1993) 1529-1537.

[13] D.R. Noble, D.L.H. Williams, Nitric Oxide-Biol. Chem. 4 (2000) 392-398.

[14] F. Schiele, Y. Artur, D. Bagrel, C. Petitclerc, G. Siest, Clin. Chim. Acta. 112 (1981) 187-195.

15] P.D. Cornwell, J.B. Watkins III, Biochim. Biophys. Acta 1545 (2001) 184-191.

[16] D. Bagrel, C. Petitclerc, F. Schiele, G. Siest, Biochim. Biophys. Acta 658 (1981) 220-231.

[17] C. Petitclerc, F. Schielem, D. Bagrel, A. Mahassen, G. Siest, Clin. Chem. 26 (1980) 1688-1693.

[18] H.E. Solberg, L. Theodorsen, J.H. Strömme, Clin. Chem. 27 (1981) 303-307.

[19] J.W. London, L.M. Shaw, D. Fetterolf, D. Garfinkel, J. Biochem. 157 (1976) 609617.

[20] M.A. Zoroddu, S. Gladiali, N. Marchettini, R. Dallocchio, Trans. Metal Chem. 20 (1995) 351-355

[21] L. Dvorakova, J. Krusek, F. Stastny, V. Lisy, Biochim. Biophys. Acta 1292 (1996) 163-167.

[22] A. Del Corso, M. Cappiello, F. Buono, R. Moschini, A. Paolicchi, U. Mura, J. Biochem. Biophys. Methods 67 (2006) 123-130.

[23] D.S. Lee, J.C. Evans, S.J. Robins, P.W. Wilson, I. Albano, C.S. Fox, T.J. Wang, E.J Benjamin, R.B. D'Agostino, R.S. Vasan, Arterioscler. Thromb. Vasc. Biol. 27 (2007) 127-133 